\title{
MUNICIPAL WASTE MANAGEMENT CHALLENGE OF URBANIZATION: LESSON LEARNED FROM PHITSANULOK, THAILAND
}

\author{
Sarintip TANTANEE ${ }^{12}$, Suthi HANTRAKUL ${ }^{3}$
}

DOI: 10.21163/GT_2019. 141.17

\begin{abstract}
:
As the world rapidly move toward urban, the most important by-product is the municipal solid waste (MSW). The amount of MSW is growing faster than the rate of urbanization. This posts challenge on environmental sustainability. Poorly managed MSW causes high impact on health, environment and economy. Several cities in Thailand have faced with this problem for decades. The ways of coping with MSW are different from city to city. Phitsanulok is one of the rapidly growing city in lower Northern Thailand. The city put their effort to find the appropriate model for MSW management through the last $20 \mathrm{yr}$. During 1999 to 2006, the city had received the support from Deutsche Gesellschaft für Internationale Zusammenarbeit, GmbH (GIZ) to do technical research and set various campaigns in MSW management. More than decade, the city had developed their own model on MSW management to reach the goal of being green and clean city. The city initiated the idea of "zero landfill" and set as their target. The model includes not only process of MSW management but also development of community based solid waste management (CBM) training course to disseminate and share their knowledge to other cities including the neighbouring countries.
\end{abstract}

Key-words: Zero Landfill Policy, Community Based Solid Waste, Municipal Solid Waste, Phitsanulok Model, Mechanical Biological Treatment, Training Course.

\section{INTRODUCTION}

World Bank (Hoornweg \& Badha-Tata, 2012) estimated that almost 1,300,000,000 t of municipality solid waste (MSW) are generated globally every year and expected to increase to $2,200,000,000 \mathrm{t} \mathrm{yr}^{-1}$ by 2025 . The waste generation per capita rate varies from city to city, depending on the standards of living. This rate tends to be much higher when the rural area moves toward to urban. This rate is also expected to increase from approximately 1.2 to $1.42 \mathrm{~kg} /$ capita/day in next $15 \mathrm{yr}$. It can be stated that MSW is directly linked to urbanization and economic development. It is claimed that urban residents generate two to three times more solid waste than rural citizens (Hoornweg \& Thomas, 1999). In developing country, however, the factor including population increasing, economic development, rapid urbanization and the improving of living standard have accelerated the waste generation (Minghua et al., 2009). Therefore, solid waste is generally considered as one of urban problems. Moreover, the issue of environmental sustainability becomes more important which makes MSW management more challenged. The preventive measures regarding waste generation and recovered useful materials and energetic power should be

\footnotetext{
1 Naresuan University, Center of Excellence on Energy Technology and Environment, Faculty of Engineering, Thailand, sarintipt@nu.ac.th;

2 Naresuan University, Department of Civil Engineering, Faculty of Engineering, Thailand;

3 Phitsanulok Municipality, Thailand, suthi3@hotmail.com
} 
done prior to final waste disposal in landfills (Manoiu et al., 2013). Most of Southeast Asian countries are developing countries of which local governments are facing with the problems of MSW. The problems include the increasing of waste generation, the burden of high costs on MSW management, the lack of understanding over a diversity of factors that affect the different stages of waste management and linkages necessary to enable the entire handling system functioning (Guerrero et al., 2013).

Phitsanulok municipality is one of the rapidly growing cities in Lower Northern Thailand. The municipality realized how serious MSW issue was, they had requested for the support from Deutsche Gesellschaft für Internationale Zusammenarbeit, GmbH (GIZ) since 1999. The municipality received support in term of expert's adviser to do technical research as well as set various new campaigns for the city in MSW management during 2000 to 2006. More than decade, they had developed their own model on MSW management in order to reach the goal of being green and clean city. The objective of this paper is to share their knowledge on their developed model as well as introduce their community based solid waste management (CBM) training course.

\section{PHITSANULOK MODEL}

Phitsanulok Municipality is the city locates in Lower Northern Thailand of which location is shown in Fig.1. There are 33,000 households in the city with the number of registered inhabitants is about 90000 whereas the number of non-registered inhabitants is around (50 000 to 100 000). Before 1999, the total MSW to disposal was around (120 to 140) $\mathrm{td}^{-1}$.

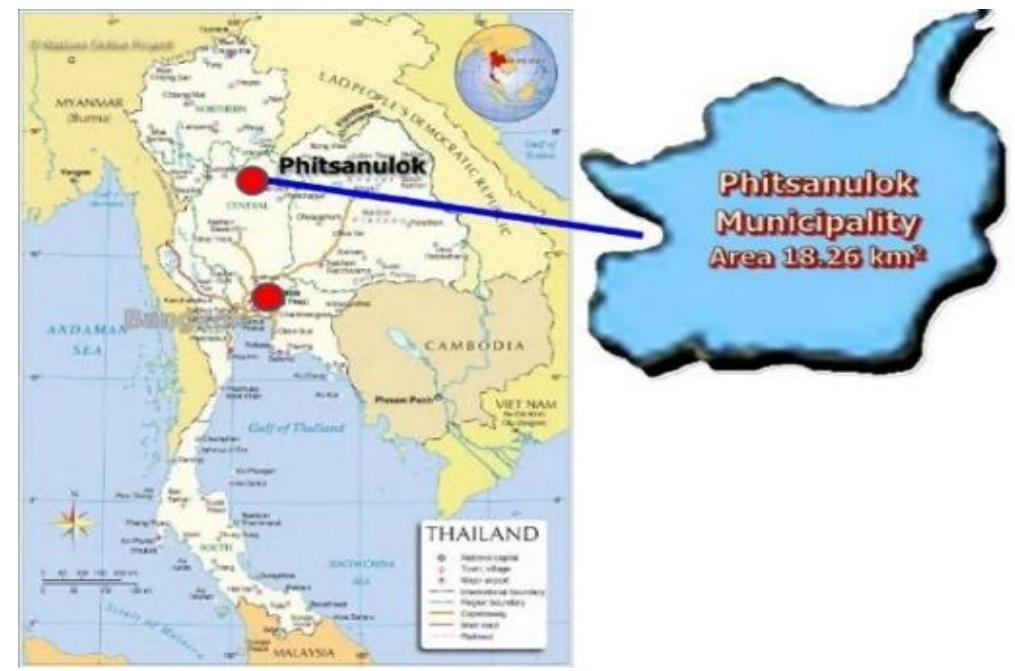

Fig. 1. Location of Phitsanulok city.

It was found that there were several problems in MSW management at that time which included (1) lacking of awareness about waste, (2) high amount of organic material in MSW, (3) lacking of technological know-how needed for modern waste management, (4) lacking of cooperation among the concerned local authorities and central government departments, and (5) subsidizing system of waste management. The city realized that MSW problems would be more serious and tended to be difficult to handle. In 1997, the city 
started to study the solid waste management system. Then, the city with Naresuan University (NU)'s assistance, had requested the technical support from German organization. In 1999, with the support from GIZ, the city launched the Joint Thai-German Solid Waste Management Programme. From 1999 to 2006, the city with the academic assistance from German experts and the researchers from NU had focused on improving their solid waste management as well as searched for appropriate MSW management model for the city. The outcomes of 7 years works were not only the building community's awareness on MSW but also a developed model of waste management for the city.

In general, there are six functional components of the solid waste management system which are (1) waste generation, (2) waste handling, separation, storage and processing at the source, (3) waste collecting, (4) waste transfer and transport, (5) waste separation, processing and transformation, and (6) disposal [Hayat 7Sheikh, 2016]. By considering through these functions, the city started by analyzing the component of the MSW which found the waste component as shown in Fig.2. More than $80 \%$ of the waste were vegetable and putrescible material $(41.2 \%)$ and saleable material $(40.2 \%)$. In the initial stage, the city promoted the 3Rs idea of Reuse, Reduce and Recycle (Samiha, 2013) to the community in order to create the community based solid waste management in the city. The city also had considered the appropriate way to cope with MSW. To avoid the dioxin formation from ineffective waste incinerator, the city, then, decided to construct the sanitary landfill as well as finding the way to extend landfill life by reducing the amount of waste.

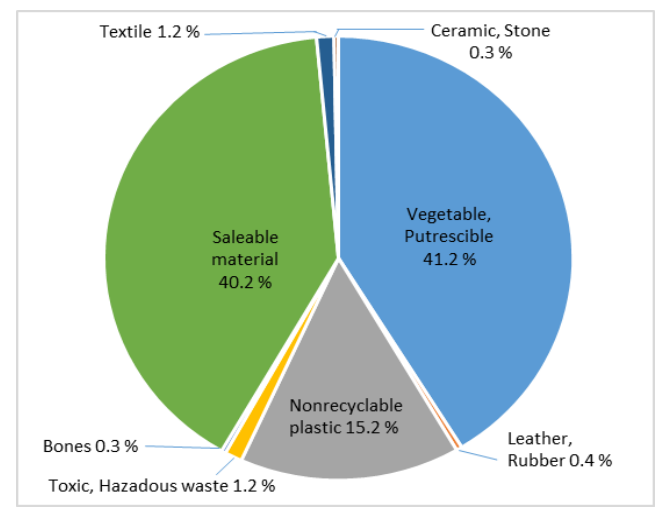

Fig. 2. Waste component of Phitsanulok city.

Through more than decade, Phitsanulok Municipality with the support from GIZ had developed their MSW management model that they finally found the most appropriate one for their city. The model had been developed based on the concept of "public participation" as well as "integration among the relevant authorities". The goals of the model are not only for MSW management in Phitsanulok but also for disseminating and sharing their model and knowledges through the training course. Fig. 3 shows the components of issues in "Phitsanulok Model".

At the first stage, the city promoted the 3 Rs concept to the community by setting up environmental protection volunteers. These volunteers were the key persons to help building awareness through several activities such as city campaigns, mobile units, workshop and training and door knocking activity, as shown in Fig.4. Based on 3Rs principle, saleable materials can be sorted for selling; organic waste, kitchen waste and 
other organic material can be separated for composting which can be done both in household and community level. The hazardous waste have to be sorted out, collected and transferred to private company for special treatment. The remaining waste, which needs to be disposed, will be collected by municipal waste truck.

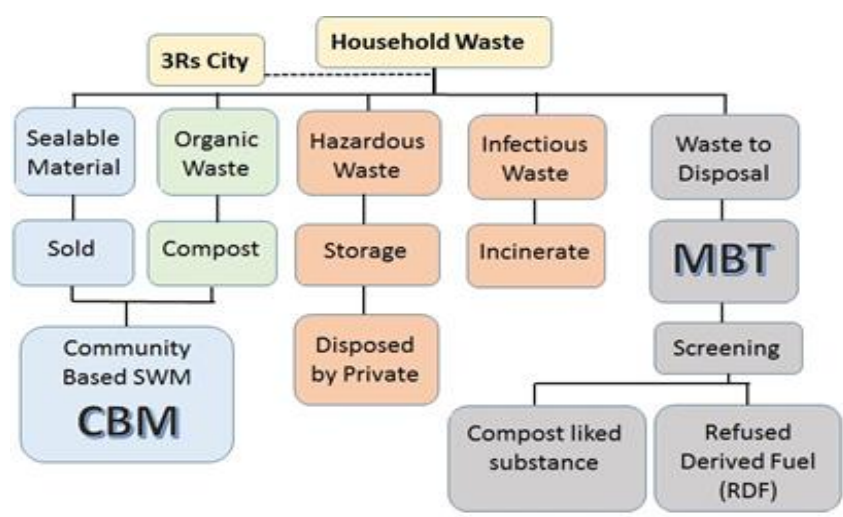

Fig. 3. The Components of issues in phitsanulok model.

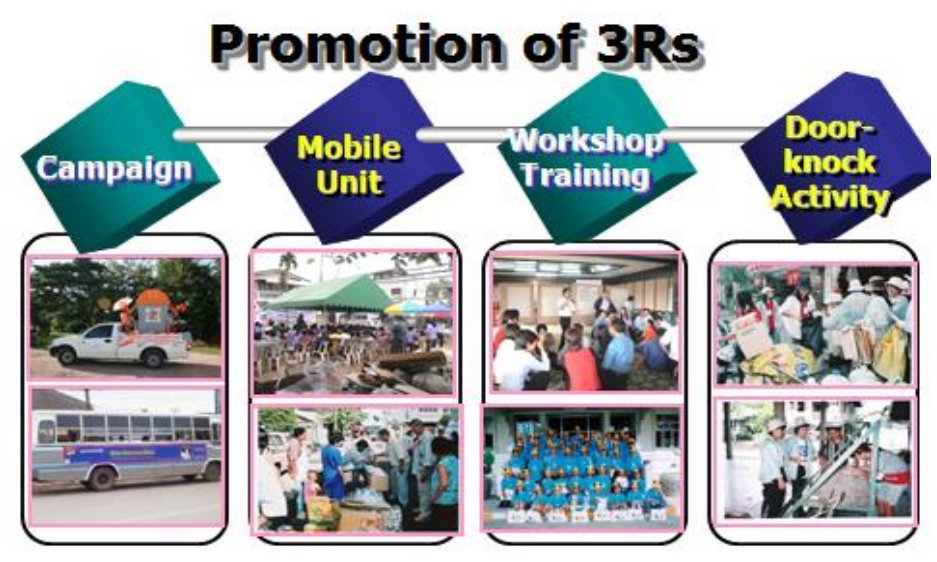

Fig. 4. 3Rs promotion to build public awareness.

Within the first year of the project, they succeeded on reducing waste from household which is obviously shown, in Fig.5, the abrupt decreasing of waste to disposal in 1999.

In 2005, Phitsanulok municipality under GIZ's supervisor had done the research on Mechanical Biological Treatment (MBT) process for the disposal waste. MBT is widely known as the mix process between mechanically removing some parts of waste and biologically treating, so the residual fraction is smaller (Archer, et.al, 2005). The combined process of MBT is flexible, and can use several types of biological and mechanical process. Mechanical process can be either machine or man power separating type whereas biological process may include Bio-drying, Anaerobic digestion and composting. The city had developed their own MBT process which took nine months to complete MBT process. 


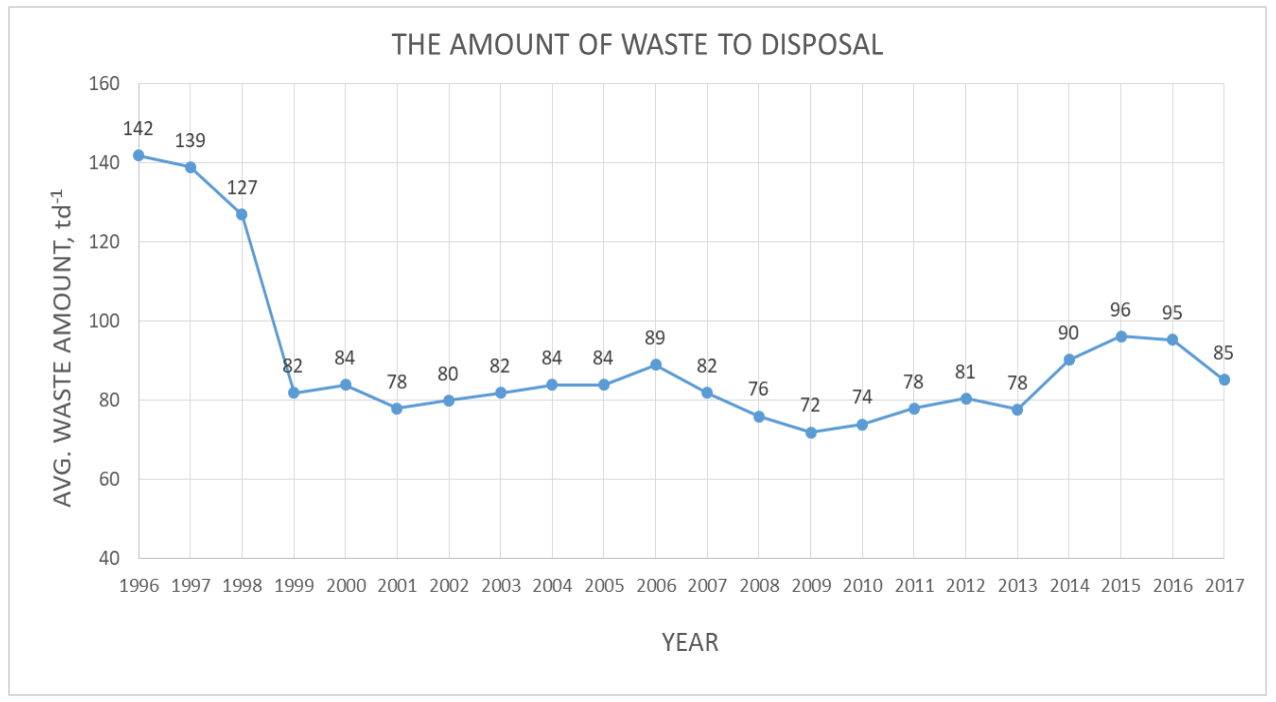

Fig. 5. The average amount of waste per day in Phitsanulok city.

Using MBT process, there is less unpleasant odor emission from landfill and landfill life can be extended up to ( 2 to 2.5) time. By-product of the process is the leachate that can be used to produce the biogas, as well. After nine months, the organic material had already been composted. The residual is low moisture content material that after passing through the screening, the compost-liked output (CLO) will be received. The properties of CLO is similar to organic fertilizer. However, it is recommended to avoid using CLO on the agriculture of food products because of the possibility of contamination from the incomplete waste sorting process. The remaining after CLO separating is high caloric fraction or refuses derived fuel (RDF). The rate of RDF production per tone of MSW varies depending on the type of collection, treatment process and quality requirement which can vary between 23 and $50 \%$ by weight of waste processed (Gendebien et al., 2003). RDF can be used to produce energy which is through either pyrolysis process or directly burned as fuel. Table 1 shows the heat value of RDF.

Table 1. Heat values of RDF, taken from Phitsanulok Municipality.

\begin{tabular}{|l|c|c|}
\hline \multicolumn{1}{|c|}{ Process time } & $\begin{array}{c}\text { Residual size } \\
(\mathrm{mm})\end{array}$ & $\begin{array}{c}\text { Heat Values } \\
\left(\mathrm{J} \mathrm{g}^{-1}\right)\end{array}$ \\
\hline Five months MBT & $<10$ & 6122 \\
& 10 to 40 & 15234 \\
& $>40$ & 33801 \\
\hline Nine months MBT & $<10$ & 5680 \\
& 10 to 40 & 18810 \\
& $>40$ & 38320 \\
\hline
\end{tabular}

It is shown that the obtained heat value of RDF is slightly different between process time of five and nine months. And, to minimize the size of MBT field, therefore, the most effective time for producing RDF is five months. Now, a cement company has taken RDF from the city to be used as fuel in the cement incinerator. According that temperature in the incinerator of cement producing is higher than $1000{ }^{\circ} \mathrm{C}$, there is no dioxin generating from 
the burning process. So, it is confident that there is no environmental impact as air pollution from the process of burning RDF.

Following the process of Phitsanulok model, the remaining waste in the sanitary landfill is very small, the city, then, initially set their policy on MSW management as "zero landfill" policy.

\section{CBM TRAINING COURSE}

Through more than decade of finding the appropriate solid waste management (SWM) model, the city's staffs not only had developed their own technical process of SWM but also had learned the community based SWM. Moreover, the attitude of people in the city concerning to SWM also had changed to be more participated from year to year. Therefore, GIZ and Phitsanulok Municipality agreed to develop a training course on Community Based Solid Waste Management (CBM) at the end of the joint program, which both training manual and facilitator manual had been developed. At that time, it was planned to disseminate and share the knowledge of CBM to only at least five municipalities in Thailand. However, the issue of SWM is very important as the key of social work for every city, it is challenged to implement this course to distribute the knowledge as well as exchange the ideas of MSW management among cities. So, the course has been disseminated to more than 100 local governments through the annual training of Local Agenda 21 (LA21) project of the Department of Environmental Quality Promotion (DEQP), Ministry of Natural Resources and Environment. Fig. 6 shows the components of CBM.

There are three levels of courses, which are the course for policy maker, operator and people. Each level has been designed for the different qualifications of the participants. The objective of the course is to assist the local governments to understand the principle of modern SWM with the international guidelines for SWM such as Polluters Pay Principle (PPP) and Cost Benefit Analysis (CBA) (Khan, 2015). However, the course does not focus in depth of SWM technology. It emphasizes on the practical issues that people need to know including saleable material, household bin, composting, garbage-bin-free in the community, frequency of MSW collection and collecting fee.

In 2006, the Phitsanulok Municipality with this course received Dubai International Award for best practice to improve the living environment. In 2011, Municipality also received the award of Asean Environmental Sustainable City (ESC) Model Cities, funded by Japan-Asean Integration Fund, to improve the course as well as encourage to provide the training for other cities. This improved course still has been using through the national training for local organization of DEQP.

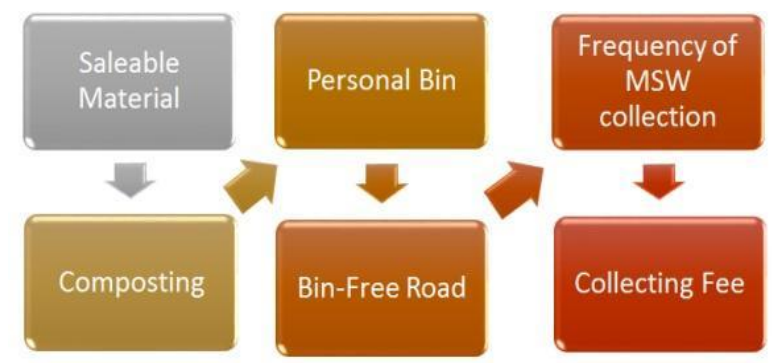

Fig. 6. The component of CBM. 
Furthermore, the city has stepped forward to international cooperation as well as enhances their activities from SWM to green and clean city. With the support from Institute for Global Environment Strategies (IGES), the city participated in the project of Technical support for City Assessment and Action Plans for Short-Lived Climate Pollutants (SLCP) Emissions Reduction in 2013 to 2014. During the Climate and Clean Air Coalition (CCAC) conference at Sao Paulo, Brazil on September, 2014, it was announced that Phitsanulok city, one of 26 cities in the world, was a prototype city in SWM.

As Sustainability Development Goals (SDGs) was adopted in 2015 (UNESCO, 2017), the purposes of this course has been enhanced to cover not only to provide knowledge about SWM but also stimulate the local agencies to recognize in Goal 11 of Sustainable Cities and Communities of SDGs. The city, then, expected to disseminate and provide the training of their model to at least 150 local cities within 2020 and expand to 1000 cities in the future.

\section{CONCLUSIONS}

MSW management is the significant work of the city services. The problem of MSW management tends to be more complicated when the rural area moves toward to urbanization. It is the multi-dimension issue that incorporates political, institutional, social, environmental, and economic aspects. To improve the SWM, it is required efforts to raise public awareness, increase funding, build expertise, and invest in infrastructure. In order to make it been sustainable, the most important thing is to create the public awareness.

Phitsanulok Municipality is one of the successful story that is not only on developing their own SWM process but also inspiring the public awareness of the community toward SDGs. Moreover, it is incidentally that the city's staffs have also been developed through the years of SWM model developing. Learning from the experiences of Phitsanulok municipality is able to assist the other city to start improving their own model of SWM more easily.

\section{ACKNOWLEDGEMENT}

The information supported from Phitsanulok Municipality is acknowledged.

\section{REFERENCES}

Archer, E. Klein, E. \& Whiting, K. (2005) Mechanical-Biological-Treatment: A Guide for Decision Makers Processes, Policies and Markets, Technical \& Business Review, Juniper Consultancy Services Ltd., Gloucestershire, UK.

Gendebien, A., Leavens, A., Blackmore, K., Godley, A., Lewin, K., Whiting, K.J., Davis R., Giegrich, J., Fehrenbach, H., Gromke, U., del Bufalo, N. \& Hogg, D. (2003) Refuse Derives Fuel, Current Practice and Perspectives, WRc Swindon, Blagrove, Swindon, Wiltshire.

Guerrero, L. A., Maas, G. \& Hogland, W. (2013) Solid Waste Management Challenges for Cities in Developing Countries. Waste Management, 33(1), 220-232.

Hayat, S. \& Sheikh, S.H. (2016) Municipal Solid Waste: Engineering Principles and Management, Malik Sirajaddin \& Sons, Lahore. 
Hoornweg, D. \& Bhada-Tata, P. (2012) What a Waste: A Global Review of Solid Waste Management, World Bank, Washington D.C.

Hoornweg, D. \& Thomas, L. (1999). What a waste: solid waste management in Asia, Urban Development division, World Bank, Washington D.C.

Khan, M. R., (2015), Polluter-Pays-Principle: The Cardinal Instrument for Addressing Climate Change, Laws, 4, 638-653.

Manoiu, V., Fontanine, I., Costache, R., Pravalie, R., and Mitof I. (2013) Using GIS Techniques for Assessing Waste Landfill Placement Suitability. Case Study: Prahova County, Romania. Geographia Technica, 8(2), 47-56.

Minghua, Z., Xiumin, F., Rovetta, A., Qichang, H., Vicentini, F., Bingkai, L., Giusti, A. \& Yi, L. (2009) Municipal Solid Waste Management in Pudong New Area, China. Journal of Waste Management, 29(3):1227-1233.

Samiha, B. (2013) The Importance of the 3R Principle of Municipal Solid Waste Management for Achieving Sustainable Development. Mediterranean Journal of Social Sciences, 4(3), 129-135.

UNESCO, (2017) Education for Sustainable Development Goals: Learning Objectives, United Nations Educational, Scientific and Cultural Organization, Paris. 